\title{
ASPECTS OF RURAL DEVELOPMENT IN PRIMITIVE AREAS ${ }^{1}{ }^{2}{ }^{2}$ )
}

\author{
J. H. DE HAAN \\ Division of Rural Economy of the Tropics, Agricultural University, \\ Wageningen, Holland
}

The following observations are confined to the primitive sectors of underdeveloped areas, particularly Equatorial Africa and New Guinea. It appeared necessary to make this restriction since there is so much variation in the degree of development that it would have necessarily led to vagueness had the discussion dealt with underdeveloped areas in their entirety.

Underdevelopment is a relative conception and moreover a very complex phenomenon in which a great variety of factors may come into play. It is difficult to provide a clear and satisfactory definition of the term and most attempts at formulating it are unsuccessful.

In practice, however, there is not so much need for an exact formulation; it is sufficient to state that in these areas the development of prosperity is below the potential capacity. One might add to this that generally these areas are poor and therefore need assistance from outside to improve their position. In situations like these, there are of course good reasons for offering this help in the form of technical assistance.

It might also be said that within this group of underdeveloped countries the primitive areas are furthest removed from the state of prosperity envisaged by us as a possible ideal. This refers to material welfare, and in the first place nutrition and health; next, the educational level; and finally the social organisation and position of the individual in society.

Without doubt it would be possible to extend this summary, to arrange it differently or give further details, but the essential point is that these and other welfare factors have to be qualified as "poor" or "low".

That under such conditions there may be "good reasons" for giving assistance is a conclusion drawn by ourselves, but this by no means implies that such assistance is felt as a "need" by the primitive peoples themselves. And even if this should be the case to some extent, the question still remains whether the people concerned really understand what this development implies, whether they are ready to make the necessary effort, and possibly alter their way of life and make the needed sacrifices.

If there is no such willingness, or if it cannot be created, it is fairly certain that the development project will be doomed to failure, as has already happened in several cases.

We shall therefore have to try to arrive at the best possible evaluation of this need, i.e. of what we term a "better living". In many cases, however, the

1) This article is based on a lecture given on November 20, 1957 at the Tropical Agricultural Days held in Wageningen on November 19 and 20, 1957.

2) Received for publication December 14, 1957. 
lack of actual information and experience makes this difficult and in other cases the data may be misleading. Enthusiasm originally shown by the population may die out because the gains of modernisation do not come up to expectation, or the necessary labour is considered to be too heavy or too unattractive, or necessary reorganisation and discipline no longer finds appreciation. The results of group farming in British-controlled East African territories have in most cases proved to be disappointing although they often seemed very promising at the start.

Hence the question which arises is firstly whether a development campaign or a development project is technically possible and whether it is economically justified, in the broadest sense of the term, and secondly there is the question as to whether the measures to be taken are suitable or desirable from the human and social point of view.

As a consequence a conflict situation may arise between two realities, a reality of facts as determined by technical, economic and demographic circumstances, and secondly a reality of sentiments determining the will of the people to co-operate in and contribute to the development of its own welfare.

Owing to the numerous failures in development work after the first optimistic post-war years (the period in which the "know-how" concept was paramount) we have been forced to realize that this sentiment is just as potent a reality as the technical justification of a development project. It should therefore not been overlooked.

This sentiment may express itself in different ways. In some cases we have a situation where the population prefers to maintain its present way of life. In other cases the population may desire more than is actually possible. The Mokwa Scheme in Northern Nigeria may serve as an example of the first situation. This Scheme was planned as a centrally administered mechanised agricultural project in which the population were to participate as sharefarmers. It promised increased production of food and commercial crops, directly benefiting the population who were partners in the scheme. The project proved to be completely unsatisfactory as it was unable to give anything additional to a people who already felt satisfied in its present condition. The local farmer did not regard the increase in welfare as a sufficient reward for the discipline which such a project always entails.

The Trinidad land settlements are another example which illustrate this situation. As local farm-economic research showed, even without large capital investments in which the State would no doubt lend a helping hand, the individual plots of these projects would give considerably higher production than could be attained on the small traditional farm. In this case also most of the farmers did not make use of the possibility of increasing prosperity.

The Lelydorp plan in Surinam is a similar example. Provisional data showed that the small, simple units of this project would suit the Surinam farmer better than the rather larger and more complex smallholdings, even though the latter were planned on a technically and economically sound basis and seemed likely to provide the family with a much higher income than that derived from the small units. For both these schemes the planners proved to have been over-ambitious. It appeared that the unsatisfactory results were not 
merely a question of unwillingness, as in the Mokwa Scheme but also lack of ability, and it is in this connection also that the importance of education and leadership comes clearly to the fore.

This factor is even more strikingly demonstrated when we assume the second of the two above-mentioned cases to apply, viz, when the development urge does not lay behind potentialities but exceeds them. As an example of this I would mention the Ajamaroe district of the Vogelkop area in Dutch New Guinea. In this district the natives had become impressed by the "glamour" of the U.S. army under Mac Arthur which for some time during the war had its headquarters at Hollandia, the capital of the territory. The population was completely under the spell of the glittering display of luxury and power and wished to reach this highly desirable state as soon as they could. In Ajamaroe the natives even went so for as to burn the traditional effects (known as "kain timoer") which had hitherto governed the religious and also the economic life of the clans. And to replace these effects, they demandied without more ado, a tractor. Naturally this gave rise to various problems, but they all led to an acculturation conflict which even resulted in an acculturation drama near the Wissel lakes in another part of New Guinea. And this acculturation is a reality which has to be treated as such; in all cases something has to be done about it, if not by means of the tractor then possibly by something else capable of properly satisfying what in this case is an exaggerated desire for a radical change in living conditions. Consequently we shall have to try and find a compromise in the conflict between the reality of facts and the reality of sentiment.

This conflict will not always be expressed in the same primitive way but in many cases it manifests itself just as forcefully and aggressively. This conflict is very wel understood by the British in Equatorial Africa where a solution is being sought by allowing the African to participate directly in the development policy on the land. In this connection I would mention the Community Development movement which I will discuss later. Unlike the French who take as their starting-point the economic development under a paternalistic régime, in British territories the object is to transfer government on a local level, viz. as a continuation of indirect rule. Therefore, native councils and native authorities have been created which are given administrative powers for the purpose of settling native welfare problems. In this way the Government satisfies the aspirations of Africans who desire a share in the conduct of their own affairs.

It may be concluded from what has been said before, that to lead a primitive people to a higher level of prosperity is a particularly delicate undertaking. In the first place because usually very little information is available about the country and its inhabitants, a matter I shall revert to below, and secondly, and most important, because it is difficult to forecacst and calculate how the development plan will progress. Hence this development is a fairly lengthy process and also subject to numerous vicissitudes and disappointments.

This can be most clearly seen with respect to the financing problem. In these areas a great deal of capital is invested which has to be paid for by 
means of increased production. The native population has to make its contribution, and it is desirable and logical that it should begin to do this at an early stage of its development. Under these circumstances direct taxation generally is an inefficient method, particularly as these areas are difficult or impossible to supervise for fiscal purposes. For this reason the native contributions will preferably be levied at times and places at which they can be made available, for instance when the product is offered for sale on the market.

In this connection I would mention the Marketing Boards which have been set up since the war in the British territories of Africa. The prime task of these Boards was most certainly not to levy taxes but to control the produce trade, for example by controlling the home market price of agricultural produce. The object of this was to protect the African farmer against fluctuations in world market prices and thereby promote peaceful economic development, and at the same time to counteract excessive expenditure by consumers in boom years and ensure a given standard of welfare during periods of depression. As a result of the favourable post-war trend in prices, which could not have been foreseen in the first instance, these Boards have nevertheless been able to accumulate financial reserves which could be usefully employed for carrying out further welfare projects. With this money it has been possible to finance development schemes, so that in this way the small producer has been able to make an important contribution towards his own development.

The same aim may also be observed on a smaller scale and more incidentally in a number of individual projects. For instance, in a Farm Betterment Scheme in Northern Rhodesia the farmers participating are paid a lower price for their maize crop so that the funds thus created may be used for carrying out public utility work as e.g. providing drinking places for cattle, or controlling erosion, and also for purchasing fertilisers and agricultural implements and awarding bonuses to farmers whose farms render fair contribution to the development programme.

A different system is adopted in a number of "paysannats" in the Belgian Congo. For instance, in the province of Babua in Northern Congo the authorities are helping the participating farmers to build better houses. Good houses are built for them and they are required to repay the building costs over a period of ten years. In this way part of the income of farmers in these paysannats is removed from the sphere of direct consumption.

We see then, that measures of this kind are not carried out for fiscal purposes, or not exclusively so, but are to be primarily regarded as arrangements made in the interest of production, of the regulation of consumption and for re-investment as well. The importance of such measures is immediately obvious in the case of a people who have been all too suddenly moved from a sphere of primary self-subsistance to a considerably higher level in a money economy and have little opportunity for productive investment in their own traditional crofter farms. Hence this is not only a problem of improving income but also of spending it. In this connection I might also mention the co-operatives in Africa which unlike those in western Europe have not sprung from individual initiative, but are usually both state-promoted and controlled.

In view of all these uncertainties it is understandable that attempts have been made to organise and to finance agricultural production and development 
on a more solid base. As stated earlier, the traditional smallholding is not a very attractive object of capital investment. It is thought therefore that production could be better ensured under exclusive control of centrally administered and financed agricultural projects provided with up-to-date equipment.

The problem has been approached in this way in French West Africa, for example, and particularly in Senegal and French Sudan. Moreover in this vast area there were several reasons which made the speeding up and likewise the future ensurance of agricultural production a matter of urgent concern. In the first place there had been a gradual increase in food shortages as a result of the great increase in population, and a shift of the population from rural to urban areas, so that in Dakar it had become necessary to import everincreasing amounts of rice. It was deemed necessary that West Africa should produce this rice herself.

Secondly, the expansion of native cultivation of commercial crops, especially the groundnut in Senegal, led to an alarming state of erosion and soil exhaustion. The traditional agricultural pattern of extensive shifting cultivation was disturbed, resulting in soil degeneration, and it was therefore thought that in this respect also a centrally administered organisation and up-to-date equipment would afford a better means of preventing soil erosion.

This led to the creation of the Office du Niger in the Sudan and the Casamance project in Senegal. The Office du Niger cultivates rice and the Casamanse project mainly groundnuts. Thus these projects had as their object an improvement in the home supplies of food as well as the enlargements of exports and the securing of the fertility of the soil. What typifies both projects is that the native population are directly included in the production scheme, inasmuch as the land is divided up into parcels which are allotted to the farmers. These farmers are joined in an agricultural organisation in which they promote their communal and individual interests. The ploughing of the land is done by tractor power under the direction of these organisations, the cost being defrayed by the individual farmers. At the same time these organisations regulate the sales of produce to the Office du Niger, thus ensuring the farmers a higher income than they would obtain as unprotected and ill-informed individuals. They make a contribution to the general costs of the project, but they also receive the full revenue of their farms. This arrangement has led to a considerable improvement in the welfare of the participating farmers. Moreover the farmers' organisations, via their representatives can exercise some effect in the general management of the project, although this influence is limited in practice and it is the Government that ultimately decides the production policy. In view of the scope and nature of the project and the interests involved, this is entirely justified.

In addition to this Office du Niger and Casamanca in French West Africa, several similar projects are know in Equatorial Africa in both French and British territories. Although in most cases too little time has elapsed to justify an opinion, a number of projects seem to be promising. On the other hand, other similar projects clearly are marked failures. There may have been technical or financial difficulties, or the preliminaries have been inadequate, while in other cases the native population did not provide the necessary cooperation. In this case such projects are oocasionally reduced to the scope of pilot schemes in which the various land development possibilities are realised on a 
much smaller scale. Thus the ambitious and famous groundnut project in Tanganyika was converted into the Nachingweo pilot scheme, and the same course is being adopted in Nigeria with the Mokwa scheme referred to above. In these pilot schemes most attention is given to mechanisation and cultivation of commercial crops, as well as food crops aimnig at a more profitable and stable form of farm management.

For these ambitious projects authority of a responsible leader and discipline of the participating farmers are essential. The same is true of the excellently organised "paysannats" in the Belgian Congo where also an organisation is superimposed. A strict organisation is necessary because these large scale enterprises are alien to a native population which usually lacks understanding and skill, as well as competent leadership and capital. The more primitive the environment, the greater the gulf between traditional production systems and modern systems in which the farmers are obliged to co-operate.

This is the difficult point. We desire to speed up development, we begin at a high level and impose a fixed system and a fixed organisation. We try to include the population in this scheme and expect them to acquire in due course sufficient understanding and skill to be able to manage and carry out the system efficiently, at least in future.

When these projects are properly planned, there is no doubt that they can play an important part in raising national as well as individual prosperity. But in view of the uncertainties mentioned above and the considerable amounts of capital which these projects entail, it may well be asked whether it would not be better to proceed the other way round and gradually build up development from the bottom.

There are a great many examples of such a development starting from the bottom. They are to be found in the French "paysannats" of West Africa and the British Farm Betterment, Land Reorganisation- and Land Development Schemes in East Africa. From the point of view of technique and organisation the set-up of these projects is far more simpler than the large-scale projects mentioned above. On the other hand, the farmers taking part in the project are left more in their own environment, and their personalities, initiative and judgement play a more important part.

But in this case also progress is slow and difficult, and since the disappointments experienced in group farming and cooperatives, it clearly appears that leadership and patience are essential conditions for the success also of farmbetterment schemes. It may happen, as in Nyasaland, for example, that an extension officer has years of work to persuade a number of families to take part in the project. Elsewhere, as in Uganda, progress is more rapid, but in general adjustment is a difficult and time-consuming process.

And thus we arrive at the social side of the problem, i.e. in how far the population, in regard to its traditional way of life, its needs and expectations is capable of assimilating economic progress. And here again the problem is more serious as the living standards of the people are lower.

In this connection reference should be made to the community development as advocated particularly in the British territories in Africa. This movement attempts to stimulate the people to self-activity, and aims at promoting better 
living standards within the community, with the active co-operation and where possible on the initiative of the people living in the community. But the addition of "where possible" also reflects the recognition that here also leadership may be expected from outside.

The field in which community development moves is difficult to survey, because it is active on so many fronts. The movement starts from the right principle that there can be no permanent economic revival without social adjustment. Therefore the social sector receives attention before the economic one.

It is difficult to find the proper balance between economic and social development. Mass literacy, for example, is one means of introducing this social evolution. On the Gold Coast (now Ghana) this movement has been enthusiastically welcomed by the inhabitants and has been a huge success. But the question now arises as to what extent this social evolution will be reflected in the economic sector, and in particular in regard to the native cultivation of cocoa, one of the pillars of Ghana's prosperity. The cocoa crop is seriously endangered by disease and soil exhaustion and moreover is producing at a low level owing to inadequate care. The effect of this social evolution and literacy on agricultural production has still to be awaited.

This economic and social relationship in agriculture is all the more urgent in the primitive areas of East Africa and New Guinea. In these really backward areas this literacy has very little reference to every day life and interests and it has to be feared that all this will create a feeling of disappointment and discontent, as well as of estrangement in one's own environment. In these areas there are still so many improvements required to supply immediate needs that a simple, and above all practical form of education with a direct appeal is all that is required at present.

In this connection it is interesting to point to the disappointing results of an agricultural Boarding school in Seroei, New Guinea, where Papuan schoolboys were given instruction in a more modern form of agriculture. When thus equipped they returned to their villages, they were unable to maintain their position in their old environment to which they had become strangers.

In the same area a far greater success was achieved when cocoa was introduced in the village to the agrarian and fishing population directly. To this end cocoa cultivation was adapted to traditional shifting cultivation, and great care was given that all agricultural measures were thoroughly well understood. The result was a spontaneous and vigorous co-operation by the farmers concerned which almost certain will lead to a considerable higher prosperity level.

Similar good results are also obtained at the farm development centre of Kepi in southern New Guinea. At this centre a simple and all-round education is given to families of representative Papuan village personalities in the district. They are brought together for twelve months, after which they return to their village. In addition to the actual agricultural activities, which is the main point, great attention is given to the care of house and garden, simple handicrafts, some knowledge of reading and writing, women education, an understanding of money, and to the provision of commodities for the satisfaction of needs. 
Now it is noticeable that both these successful farmers projects were under continuous direction of a local officer and a missionary, both of Dutch nationality, viz. two persons residing on the spot, well acquainted with the people and fully trusted by them.

I am inclined to believe that much of the success of such projects is due to this personal and continued contact. It should not be forgotten that the new ideas and means we import to these primitive communities are so strange to them that they cannot be independently assimilated at their proper value. In other words an intermediary is needed who explains and "translates" the novelty, helps to break down a passive barrier, prevents misconceptions and conflicts and may help to smooth the path for a sound acculturation.

Experience learns that Europeans may show great ability in introducing modern ideas and thinking. I would even be inclined to say that they should preferably be Europeans, since what in fact is required is a transference of skill and understanding in which the native leaders are still lacking. However it is pertinent that these foreigners are fully prepared for their task. That they become properly acquainted with the country and people and know how to adapt themselves to the surroundings and people without losing their own individuality. The latter is particularly important. A further condition should be that they know how to form useful disciples who are willing to follow in their footsteps. Modernisation has to be introduced and explained, but will only be followed if the example is given by the natives themselves in their own territory. It is obvious that these European instructors ultimately have to make place for representatives of the country itself, but not before these substitutes have been properly initiated into the new way of living and working and have successfully integrated it into their own environment.

It seems to me that there is every reason in New Guinea to expand this more personal approach to rural development. In addition to local extension officers already working in the area and in addition also to the Catholic and Protestant missionaries, it would be appropriate to select field officers now attached to the Agricultural Extension Service in the Netherlands. In most cases these field officers are farmers' sons who by nature might be very well suited to do a similar task in New Guinea. They would need a practical training beforehand in regard to tropical conditions and when entered into duties should not be overburdened with clerical work, as is so very well understood in Kenya and in the Cameroons.

I emphasize this point because I feel that a distinct and special place should be given to agricultural extension in connection with community development. It should not be forgotten that agriculture is not a new element to these people, but an activity in which they have grown up and which has become a deep-rooted part of their daily life. It occupies a central position in the farmer's existence and way of thought, and this farmer, however primitive he may be, certainly is an expert worker in his own field. Consequently this farmer will have to be approached in a more skilful and specific, and also a more insinuating way than is possible within the framework of the comprehensive approach of community development. Hence agricultural extension work has its own distinct place in community development.

It might even be asked whether agriculture would not be a means par 
excellence of giving content to rural development, a content it undeniably requires. However, on the other hand, it is stated that agriculture is too bound up with fixed tradition that it will be difficult to suggest new lines of thought along the line of agricultural improvement.

It is of course difficult to come to any generally acceptable conclusion; the situation will vary from place to place and from time to time and the development policy will be different accordingly. In all cases the introduction of new means and thoughts asks for attention and therefore a "new" crop and a new implement might arrest this attention and might bring farm modernisation to a possible success.

But whatever it may be, if we fail to include agriculture in the development project, we run the risk of alienating the farmer from his land. And should this be the case, it will both lead to abandonment of the original selfsupplying economy and to disintegration of society. We can quite safely assume that should agriculture be unable to develop in a community, or worse if it is neglected, no further form of development will be possible. It is for this reason that $I$ have urged the need of giving special attention and a special place to this agricultural development.

The manner in which this rural development is organised on a broader basis will depend on circumstances. The Bureau for Land Utilization which was established in Indonesia immediately after the war has linked its organisation in that country with the decentralised local government, a form of organisation more or less comparable with the native authorities in the British-controlled territories.

In the far more primitive inland of Nw. Guinea, a similar organisation is difficult to establish, at least at present. But here too, we should, whereever possible, aim at something more than a passive participation of the Papuan population in the work of raising living standards.

In conclusion I should like to draw attention to a further point which I consider to be very important. It is the following. Where rural development in primitive areas holds so many difficulties and uncertainties, there is all the more reason for obtaining the most concrete possible picture of the conditions regarding the land and the people, the potentialities as well as the actual situation.

A survey of this kind combined with active research, is actually the only concrete basis for development, it reveals the defects and possibilities of rural development and it should be undertaken with the greatest possible care.

We have slowly learnt by experience, and we now realise that success does not so much depend on the bold pioneer, as on the man who has ascertained himself of the facts and who therefore can form a proper idea of possibilities and risks involved. There will always be risks and they must be taken, but one has to be aware of taking them; pioneering with all its attractions can then follow in due order.

In this paper I have confined myself to certain aspects of rural development and $I$ have passed by the numerous other subjects deserving of attention in this regard. So the picture is not complete. 
I have dealt in particular with the manner in which this development may be approached in practice, and I have come to the conclusion that no general rules or particular programme can be indicated. Objectives vary in their effect and conditions and possibilities vary from place to place, as they also vary in the different stages of development.

However, predominant for every project and programme is the survey, the analysis of the land and people, a survey which should be as thorough and as many-sided as possible.

In the second place it is essential that we follow the course of the development as closely as possible, in other words that we are "on the spot" so that whenever and wherever a conflict situation arises we can do all that is possible to secure the path of progress.

It is further essential that adequate means, should be made available for this development, but without the persons who are able and willing to lead this development, such means are worthless. 